\title{
Role of Fine Needle Aspiration Cytology in Diagnosing Non-Malignant Breast Lesions
}

\author{
Dr. Shilpa M Shetty ${ }^{1}$, Dr. Priyanka Devagiri ${ }^{2 *}$, Lt. Col. Dr. U S Dinesh ${ }^{3}$ \\ ${ }^{1}$ Tutor, Department of Pathology, Shimoga Institute of Medical Sciences, Shimoga 577201, Karnataka, India \\ ${ }^{2}$ Consultant, Jindal Sanjeevani Multi-Speciality Hospital, Toranagallu 583123, Bellary, Karnataka, India \\ ${ }^{3}$ Professor and Registrar, SDM University, Sattur 580009, Dharwad, Karnataka, India
}

DOI: $\underline{10.36348 / \mathrm{sjpm} .2019 . \mathrm{v} 04 \mathrm{i} 11.010}$

| Received: 06.11.2019 | Accepted: 22.11.2019 | Published: 30.11 .2019

*Corresponding author: Dr. Priyanka Devagiri

\section{Abstract}

Introduction: Fine needle aspiration cytology (FNAC) has become popular as a valuable tool in preoperative assessment of breast masses, helping the clinician to plan appropriate management. It is a rapid, simple, cost - effective procedure with minimal complications. Aims and Objectives: 1) To assess distribution pattern of non-malignant breast lesions. 2) To evaluate diagnostic accuracy of FNAC with cytohistological correlation. Materials and Method: Cross-sectional descriptive study with the use of secondary data was done for 2 years, including all the non-neoplastic and benign neoplastic cases where FNAC on breast lumps was performed in the department of Pathology, SDM College of Medical Sciences, Dharwad, Karnataka, India. Cases where the aspirate were acellular or hemorrhagic and malignant breast neoplasms were excluded from the study. FNAC slides were collected from the departmental archive and were reviewed. Results: Of the total 339 cases, 11 (5.60\%) were males and 328 (94.39\%) were females. Age group ranged from 10 to 70 years. Fibroadenoma was the most common lesion (72.27\%). 98 cases were followed up with biopsy, out of which 95 cases were concordant and 3 were discordant. Diagnostic accuracy of FNAC was found to be 96.93\%. Conclusion: The most common benign breast lesion was found to be fibroadenoma. Discordance rate of FNAC was 3.06\%. Hence, FNAC is a valuable tool in the evaluation of non-malignant breast lesions.

Keywords: FNAC, Breast lump, Fibroadenoma, Diagnostic accuracy.

Copyright @ 2019: This is an open-access article distributed under the terms of the Creative Commons Attribution license which permits unrestricted use, distribution, and reproduction in any medium for non-commercial use (NonCommercial, or CC-BY-NC) provided the original author and sources are credited.

\section{INTRODUCTION}

Breast masses is the most common presenting complaint in females and majority of them are diagnosed to have non-neoplastic or benign neoplastic lesions [1]. Benign proliferative breast disease is a complex process that can present as a true neoplasm or sometimes represent hormone induced hyperplasia [2]. In male breast, gynaecomastia is the most common clinical and pathological abnormality encountered [3].

Breast has a remarkable ability to undergo benign hyperplasia and many carcinomas can be cytologically bland, thus causing difficulty in scrutinizing such cases under microscope. Hence, triple diagnostic parameters to be applied for evaluating breast lesions, which includes clinical assessment, mammography and cytology [4].

Fine needle aspiration cytology (FNAC) helps in making binary decision between a benign and malignant breast lesion. FNAC is an easy, cost effective, minimally invasive procedure that provides rapid diagnosis of neoplastic, hyperplastic and inflammatory masses with minimal complications. Some of the causes of diagnostic pitfalls are scant cellularity in cystic lesion, only necrotic debris on cytology that can be present both in inflammatory as well as neoplastic lesions, reactive epithelial atypia in inflammatory conditions, worrying appearance of fibroadenoma and low grade ductal carcinoma mimicking benign hyperplasia. Rarely, skin adnexal tumor, soft tissue tumor of chest wall and secondary carcinoma can mimic primary breast lesion [4]. Hence, histopathological examination should be used in conjunction with other diagnostic modalities for accurate diagnosis which in turn guides clinician/surgeon to use appropriate treatment strategies.

\section{AIMS AND OBJECTIVES}

1. To assess distribution pattern of nonmalignant breast lesions.

2. To evaluate diagnostic accuracy of FNAC using cytohistological correlation. 


\section{MATERIALS AND METHODS}

Cross-sectional descriptive study with the use of secondary data was done for 2 years in the department of Pathology, SDM College of Medical Sciences, Dharwad, Karnataka, India.

\section{Inclusion Criteria}

- All the non-neoplastic and benign neoplastic breast lumps where FNAC was performed in our department.

\section{Exclusion Criteria}

- Cases where the aspirate was acellular or hemorrhagic and malignant breast neoplasms were excluded from the study.

FNAC was performed under sterile condition using disposable $22-23 \mathrm{G}$ needle and $10 \mathrm{ml}$ syringe. Aspirated material was placed on the glass slide and smear was performed. In cystic lesion, with first prick fluid was aspirated and second prick was performed to get material from underlying solid area if any. Fluid sample after aspiration was centrifuged and then subjected to routine processing. Air dried smears were stained with Leishman stain, whereas alcohol fixed smears were stained with $\mathrm{H} \& \mathrm{E}$ stain and Papanicolaou stain. Zeihl-Neelson stain for Acid fast bacilli was done on air dried smear whenever required. Slides were collected from the departmental archive and were reviewed.

\section{RESULTS}

Of the total 339 cases, $11(3.24 \%)$ were males and $328(96.75 \%)$ were females. Age group ranged from 10 to 70 years. Spectrum of breast lesions that were encountered: Non-granulomatous inflammatory lesion $(5.89 \%)$, Granulomatous inflammatory lesion $(3.53 \%)$, Fat necrosis $(2.06 \%)$, Duct ectasia (0.29\%), Galactocele (2.94\%), Gynaecomastia (3.24\%), Duct papilloma (2.65\%), Nipple adenoma (0.29\%), Fibroadenoma $(72.27 \%)$ Fibroadenoma with fibrocystic change $(5.01 \%)$ and Benign Phyllodes tumor $(1.76 \%)$ (Table-1). Fibroadenoma was the commonest lesion $(72.27 \%)$.

Table-1: Distribution pattern of non-malignant breast lesions on FNAC
\begin{tabular}{|l|l|}
\hline Diagnosis & No. of cases \\
\hline $\begin{array}{l}\text { 1. Inflammatory - Non Granulomatous } \\
\text { - Granulomatous } \\
- \text { Fat necrosis }\end{array}$ & $20(5.89 \%)$ \\
& $07(3.53 \%)$ \\
\hline 2. Duct ectasia & $01(0.29 \%)$ \\
\hline 3. Galactocele & $10(2.94 \%)$ \\
\hline 4. Gynaecomastia & $11(3.24 \%)$ \\
\hline 5. Duct papilloma & $09(2.65 \%)$ \\
\hline 6. Nipple adenoma & $01(0.29 \%)$ \\
\hline 7. Fibroadenoma & $245(72.27 \%)$ \\
\hline 8. Fibroadenoma with fibrocystic change & $17(5.01 \%)$ \\
\hline 9. Benign Phyllodes tumor & $06(1.76 \%)$ \\
\hline TOTAL NO. OF CASES & $\mathbf{3 3 9}$ \\
\hline
\end{tabular}

98 cases were followed up with biopsy, out of which 95 cases were concordant and 3 were discordant (Table-2).

Table-2: Cyto-histological correlation of non-malignant breast lesions

\begin{tabular}{|l|l|l|}
\hline Cytological Diagnosis & No. of cases & Histopathological diagnosis \\
\hline 1. Inflammatory lesion & 11 & Mastitis (11) \\
\hline 2. Fat Necrosis & 03 & $\begin{array}{l}\text { Fat necrosis (02) } \\
\text { Infiltrating ductal carcinoma (01) }\end{array}$ \\
\hline 3. Galactocele & 03 & Galactocele (03) \\
\hline 4. Duct papilloma & 05 & Intraductal papilloma (05) \\
\hline 5. Fibroadenoma & 73 & $\begin{array}{l}\text {-Fibroadenoma (71) } \\
\text {-Infiltrating ductal carcinoma (01) } \\
\text {-Benign Phyllodes tumor (01) }\end{array}$ \\
\hline 6. Benign Phyllodes tumor & 03 & Benign Phyllodes tumor (03) \\
\hline TOTAL NO. OF CASES & $\mathbf{9 8}$ & $\begin{array}{l}\text { Concordant -95 } \\
\text { Discordant - } \mathbf{0 3}\end{array}$ \\
\hline
\end{tabular}

A case of Fibroadenoma on FNAC (Fig-1A) showed cohesive cluster of ductal epithelial cells with nucleus showing overlapping and mild nuclear atypia. Few myoepithelial cell nuclei and bare bipolar nuclei seen. Corresponding histopathology slide showed Infiltrating ductal carcinoma not otherwise specified grade I with extensive ductal carcinoma in situ (DCIS) component (Fig-1B). Another case of Fibroadenoma on FNAC (Fig-2A) showed sheets of benign ductal epithelial cells, myoepithelial cell nuclei along with few stromal fragments and many bare bipolar nuclei in the background. On histopathology, it showed features of 
Benign Phyllodes tumor (Fig-2B). In one case of Fat necrosis on FNAC (Fig-3A); many foamy histiocytes, multinucleated giant cells and necrotic background was seen. Histopathologically, it showed features of
Infiltrating ductal carcinoma not otherwise specified grade I (Fig-3B).
Diagnostic accuracy of FNAC was found to be

\section{MICROPHOTOGRAPH}

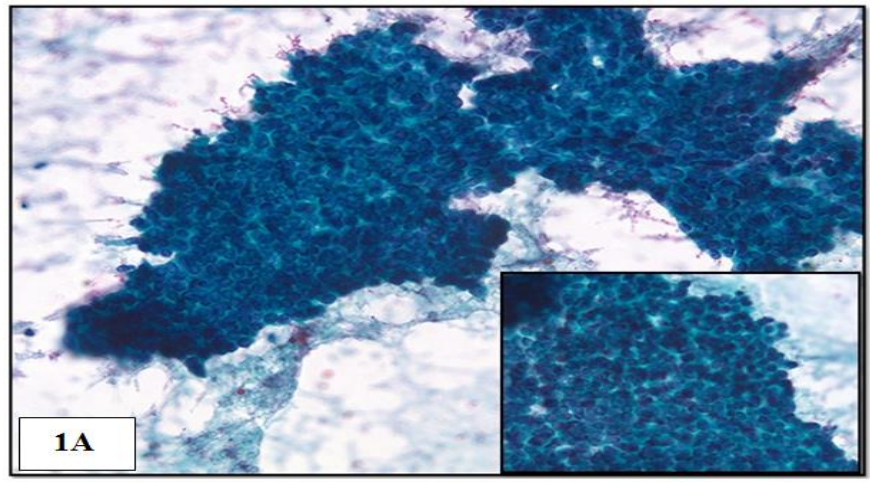

Fig-1A: FNAC- Fibroadenoma (Pap10x, inset 40x)

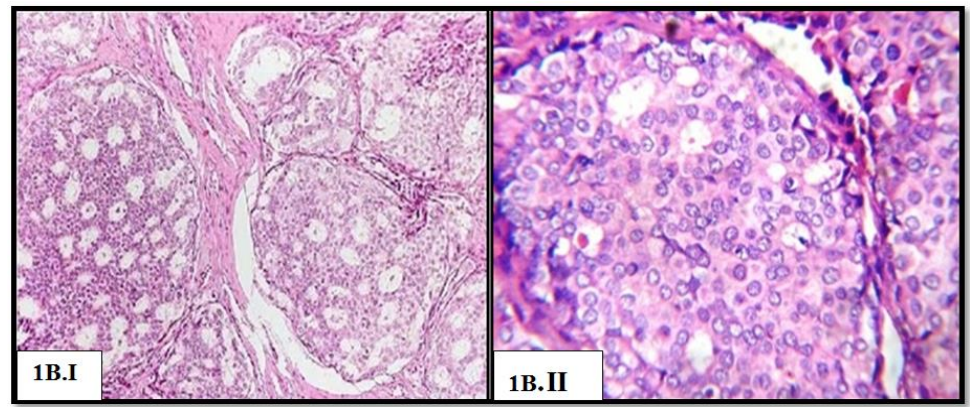

Fig-1B: Histopathology - Infiltrating Ductal Carcinoma - Not Otherwise Specified Grade I with Extensive DCIS Component; I.(H\&E 10x); II.(H\&E 40x)

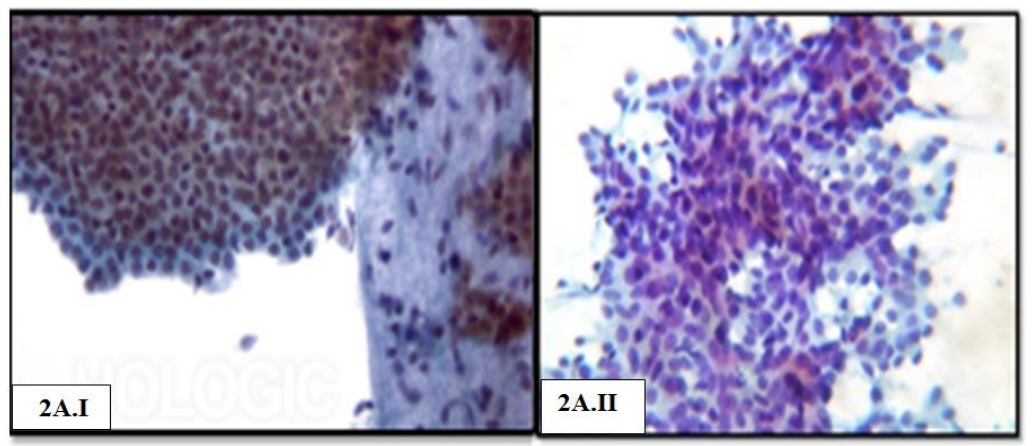

Fig-2A: FNAC- Fibroadenoma - I.(Pap 10x); II.(Pap 40x)

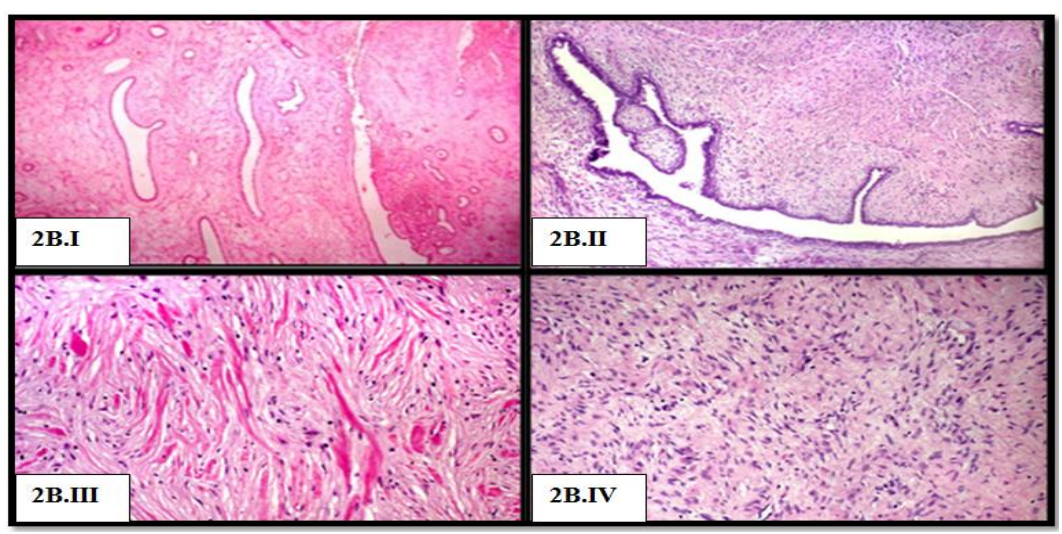

Fig-2B: Histopathology- Benign Phyllodes Tumor; I.(H\&E 4x); II.(H \& E 10x); III,IV.(H \& E 40x) 


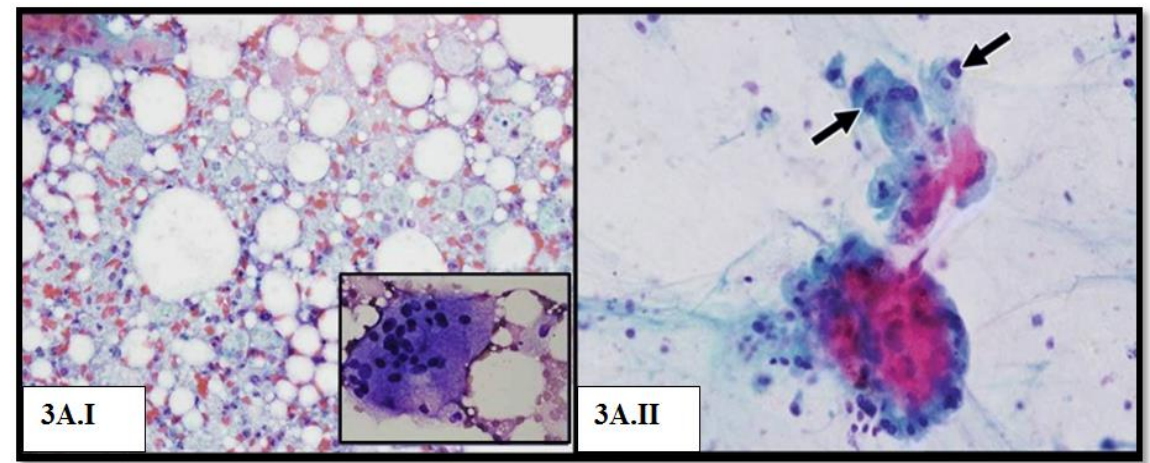

Fig-3A: FNAC- Fat Necrosis; I.(Pap stain 10x, inset multinucleated giant cell 40x); II.(Pap stain 10x, arrows- Histocytes)
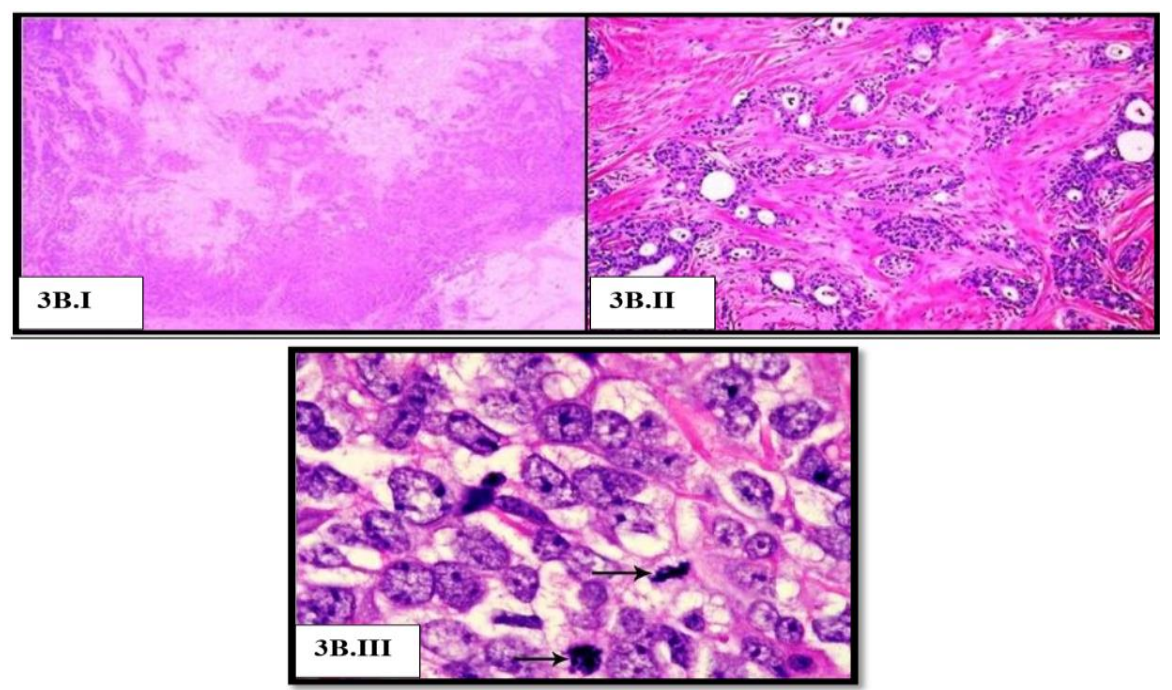

Fig-3B: Histopathology Infiltrating Ductal Carcinoma - Not Otherwise Specified Grade I; I.(H\&E 4x); II.(H \& E 10x); III.(H \& E 40x, arrows - atypical mitoses)

\section{DISCUSSION}

The present study was undertaken to evaluate distribution pattern of non-malignant breast lesions that occurs in both the gender. FNAC plays an important role in pre-operative diagnosis of breast lesions.

In the present study, age at presentation ranged from 10 to $70 y r s$. and such wide age range was also observed by Badge S A et al., [5] and Tiwari M et al., [6] affecting $10-80 \mathrm{yrs}$ and $17-56 \mathrm{yrs}$ in their respective study. $96.75 \%$ were females which correlated well with study done by Naik P et al., [7] and Gardas V et al., [8] with $97.5 \%$ and $92.9 \%$ female patients respectively.

Fibroadenoma was the commonest lesion seen in the present study with $72.27 \%$, which was similar to the study done by Badge S A et al., [5] and Naik P et al., [7] with $55 \%$ and $75.6 \%$ of fibroadenoma cases respectively. Gynaecomastia represented $3.24 \%$ of cases in the present study which was comparable with the study done by Elmadhoun et al., [1] (3\%), Albasri et al., [9] (3.1\%) and Chandanwale S S et al., [10] $(3.32 \%)$. We found a diagnostic accuracy of $96.93 \%$. Jayaram G et al., [11] found FNAC diagnostic accuracy of $97.1 \%$ in their study on non-malignant breast lumps.
In the present study there were 3 cytohistological discordant cases. A case of Fibroadenoma on cytology, was diagnosed as Infiltrating ductal carcinoma not otherwise specified grade I with extensive ductal carcinoma in situ (DCIS) component on histopathology. This false negative diagnosis occurred due to clinical presentation of small breast lump with no skin or underlying chest wall involvement in a middle aged women with extensive DCIS component in the lesion which was sampled on FNAC, and showed tight clusters of ductal epithelial cells with mild nuclear atypia, few bare bipolar nuclei were seen which was further confused as fibroadenoma. Rogers L A et al., [12] in their study found that well differentiated invasive ductal carcinoma and ductal carcinoma in situ can mimic fibroadenoma as $20 \%$ of fibroadenomas can show cytological atypia or have isolated cells with intact cytoplasm and naked nuclei are seen in some ductal carcinomas.

Another case of Fibroadenoma on FNAC was diagnosed on histopathology as Benign Phyllodes tumor. Cellular smear with sheets of ductal epithelial cells and few stromal fragments led to misdiagnosis. Veneti $\mathrm{S}$ et al., [13] in their study mentioned that hypercellular stromal fragments that are more common 
in Phyllodes tumor can be seen in fibroadenoma as well.

One case of Fat necrosis on cytology was confirmed as Infiltrating ductal carcinoma, not otherwise specified grade I on histopathology. Cytological smears showed multinucleated giant cells, histiocytes in a background of necrotic debris with few atypical cells which was considered as reactive atypia in ductal epithelial cells. Ducatman B S et al., [14] have mentioned in their study that fat necrosis can mimic carcinoma both clinically as well as mammographically and cytological smears can show histiocytes, multinucleated cells, atypical cells, neutrophils, lymphocytes, plasma cells. Study done by Kollur S M et al., [15], found that giant cells in breast carcinoma can be due to palpation granuloma or fat necrosis indicating extra-tumoral reactive process.

\section{CONCLUSION}

FNAC is minimally invasive, cost effective, out patient procedure to effectively categorize various breast lesions. High diagnostic accuracy rate makes it an effective tool which aids in appropriate management. This study aimed at knowing the distribution pattern of non-malignant breast lesions, evaluating the cytohistological correlation and analyzing the cause for 3 false negative cases. Clinical history, mammography, FNAC and histopathology should be used methodically to come to an effective diagnosis.

\section{REFERENCES}

1. Elmadhoun, W. M., Almobarak, A. O., Ibrahim, A. M., Bushara, S., Noor, S. K., Husain, N. E. O., \& Ahmed, M. H. (2015). Cytomorphology of palpable breast lesions: Diagnostic utility of FNAC in a developing country. Diagnostic cytopathology, 43(10), 825-829.

2. Rosai, J. (2011). Benign proliferative breast disease. In: Goldblum, J. R., Lamps, L. W., McKenney, J. K., Myer, J. L. Rosai and Ackerman's Surgical Pathology. Volume 2, Edition $10^{\text {th }}$. China: Elsevier; 1665.

3. Rosen, P. P. (2009). Benign proliferative lesions of the male breast. In: Rosen, P. P., Rosen's breast pathology. Edition $3^{\text {rd }}$. Philadelphia: Lippincott Williams and Wilkins; 777.

4. Howat, A. J., \& Coghill, S. B. (2003). Normal breast cytology and breast screening. In: Gray, W.,
McKee, G. T. Diagnostic cytopathology. Edition $2^{\text {nd }}$. China: Elsevier; 237-256.

5. Badge, S. A., Ovhal, A. G., Azad, K., \& Meshram, A. T. (2017). Study of fine-needle aspiration cytology of breast lumps in rural area of Bastar district, Chhattisgarh. Medical Journal of Dr. DY Patil University, 10(4), 339-342.

6. Tiwari, M. (2007). Role of fine needle aspiration cytology in diagnosis of breast lumps. Kathmandu Univ Med J, 5(2), 215-217.

7. Naik, P. (2017). Cytomorphological study of palpable benign breast lesions. International Journal of Research in Medical Sciences, 5(5), 1843-1845.

8. Gardas, V. (2018). Cytological study of breast lumps with histopathological correlation. Indian $J$ Basic Appl Med Res, 7, 185-192.

9. Albasri, A. M. (2014). Profile of benign breast diseases in western Saudi Arabia: An 8-year histopathological review of 603 cases. Saudi medical journal, 35(12), 1517-1520.

10. Chandanwale, S. S., Gupta, K., Dharwadkar, A. A., Pal, S., Buch, A. C., \& Mishra, N. (2014). Pattern of palpable breast lesions on fine needle aspiration: A retrospective analysis of 902 cases. Journal of mid-life health, 5(4), 186-191.

11. Jayaram, G., \& Gupta, M. (1994). Fine needle aspiration cytology of benign breast lumps: a review of experience with 651 cases. The Malaysian journal of pathology, 16(1), 29-38.

12. Rogers L A, Lee K R. Breast carcinoma simulating fibroadenoma or fibrocystic change by fine needle aspiration. A study of 16 cases. Am J Clin Pathol.1992;98(2):155-160.

13. Veneti S, Manek S. Benign Phyllodes tumor vs Fibroadenoma: FNA cytological differentiation. Cytopathology. 2001; 12(5):321-328.

14. Ducatman B S, Wang H H. Breast. In:Cibas E S, Ducatman B S. Cytology:Diagnostic principles and clinical correlates. $4^{\text {th }}$ edition. China:Elsevier;2014.p.242-243.

15. Kollur, S. M., \& El Hag, I. A. (2006). FNA of breast fibroadenoma: observer variability and review of cytomorphology with cytohistological correlation. Cytopathology, 17(5), 239-244. 